\title{
Brand Strategy of Shadow Play Digital Museum
}

\author{
Jiachen Zhang * \\ School of art, Hebei University of Science and Technology, Shijiazhuang,050018, China \\ *webmaster@hebust.edu.cn
}

\begin{abstract}
China's intangible cultural heritage shadow puppet shows its more than two thousand years' history. In today's era full of luminous screens, few lights are still projected on the shadow puppets. The shadow puppets only exist in the hands of some old craftsmen. Few young generations take over and inherit the skills and knowledge of the old craftsmen, resulting in the shadow puppets gradually disappear in people's sights. Besides, few people pay attention to the development and charm of traditional folk art shadow puppets. In this paper, the case analysis method is used to summarize the current situation and development trend of the digital museum in the display and navigation, the analysis of the advantages of the application, and the design principles and design methods of the digital museum user interface. It summarizes and analyzes excellent digital museum design cases at home and abroad, and sorts out and summarizes the design principles of digital museums and the specific methods of user interface design. Digital museums are in line with the development of the times. Since the exposure rate of cultural and creative products has increased in recent years, the number of visits and discussions of museums has increased frequently, which has promoted the brand image of digital museums. Digital museum website designs the improvement of cultural and creative product development, the number of people facing the increase. the digital museum is also being improved. Therefore, the construction of an online digital museum for Tangshan Shadow Play Museum is a project to promote the development of shadow puppet culture. With the vigorous development of computer technology, more and more people use digital products, so Tangshan Digital Museum is operational feasibility. It is of great significance for spreading traditional culture.
\end{abstract}

Keywords: New Media; Digital Museum; Brand Strategy; Traditional Culture.

\section{Introduction}

With the rapid development of contemporary advanced digital technology, more and more media can be used to carry out brand image design and series product design in the face of traditional culture. We should protect and innovate intangible cultural heritage or traditional art to make intangible cultural heritage alive.And in the form of expression, it should be diversified and express traditional cultural stories from multiple angles.Let the trendy traditional art truly enter the younger generation group and play with them in a daily manner.We should encourage the younger generation to participate in non-hereditary inheritance, and then develop the traditional Chinese art.

In this era of big data, lacking some online learning and viewing methods, so that viewers can appreciate the cultural colors and charms of various places on their mobile phones without leaving home. Therefore, in order to make the traditional museum keep pace with the development of the times, some innovations have been made, relying on the combination of the Internet and new media and Tangshan shadow puppetry, to create an online museum for Tangshan shadow puppetry- the Tangshan Shadow Puppet Digital Museum. A museum is a kind of art, a place to appreciate art, and visitors are educated. As time goes by, the relationship between museums and visitors has become more diverse and changeable. [1] Refining the meaning of each shadow puppet and combining it with cultural and creative products can help further the development and promotion of the traditional culture of shadow puppetry. In the design of Tangshan Shadow Puppet Digital Museum, the difference from the past is that the shadow puppet culture, which is gradually fading out of people's sights, is associated with the innovative design of new media. It will have the breath of traditional Chinese folk art Both in color and shape, and improve the exposure rate of traditional folk art shadow puppets. We should keep up with the development of the times and strive to give full play to the charm of shadow puppets. Using information visualization and comfortable and beautiful layout 
design allows users to more intuitively feel the charm of traditional culture and art. [2] We strive to carry forward Chinese traditional art and achieve the accomplishments of Chinese traditional folk art.

If traditional culture wants to get out of the boudoir, it must return culture to life and daily life. Therefore, traditional culture needs to be actively innovated, with more forms of expression to inherit and extend culture, so that the public can truly deepen their understanding of traditional culture in daily contact. By creating brand image design and cultural and creative product packaging design, young people can have a deeper understanding of the traditional culture of shadow puppets, so that traditional culture can inherit and continue traditional culture and even intangible cultural heritage in a broad sense with the help of brand image and the "shell" of cultural and creative products. These can be used as creative derivatives of traditional cultural shadow puppets and become part of the brand equity of shadow puppets.

Through the innovative redesign of Tangshan shadow puppetry, a digital museum of its own will be created for Tangshan shadow puppetry. Digitization refers to the conversion of various complex information into a measurable, easy-to-calculate and analyze digital combination through the form of numbers.[3] It is appropriate to apply digital humanities research to it to improve the level of museum construction and development.[4] The audience can browse and learn the culture and connotation of Tangshan shadow puppetry on mobile phones or computers, and they can learn about shadow puppets from books and shadow puppets' functions, customs, and production processes. It is hoped that shadow play digital museum can play an important role in the publicity of shadow puppets, and Tangshan shadow puppetry and even Chinese shadow puppetry will enter the general public's vision with a new look to a certain extent, gaining the attention of the younger generation, and promoting the development of traditional Chinese folk art.

\section{Comparison of the Development of Chinese and Foreign Digital Museums}

\subsection{Interface Design of Chinese and Foreign Digital Museums}

Due to the late start of the development of domestic digital museums, they are still in the development stage. However, there are also some museums' online websites and APPs (Applications) that have their own characteristics and sense of design. Digital museums emphasize the multi-faceted use and show the museum style from a new perspective. The concept of foreign word museums was put forward in the United States in the 1970s, and then, this idea and concept was promoted in the United States' booming economy and high-tech technology's development, and it was very successful. At that time, digital technology was in the application, development and popularization of computer technology. Some professional scholars abroad explored whether computer technology can be used in the field of museums. With the vigorous development of computer technology, the digital museum discussed by scholars has become real. Affected by the development of emerging technologies such as big data, the Internet of Things, and cloud computing, traditional museums are transforming into "smart museums".[5] Countries around the world have gradually begun to use digital technology to protect cultural heritage, changing from digital libraries to digital museums. As a new museum that has never appeared before, digital museum has become a trend in European and Asian countries.

Whether it is software or mini programs, domestic digital museums have a certain degree of similarity in page layout and page style. The design style is solemn and the website design highlights the national characteristics. For example, the digital museum design styles of the Palace Museum and the Capital Museum. And the design style of the Nanjing Museum website. The design styles of these three digital museums all show national characteristics. These design styles also exist in some software, such as "folding fan" and "mortise and tenon". They are called mobile museums. Each piece of software only introduces one traditional Chinese craft. In the design style, there are not only some traditional cultural symbols, but also the user experience. The use of music helps achieve a very rich learning, entertainment, and immersive experience. The National Museum of China attaches great importance to the management of its Sina Weibo account, and constantly updates its Weibo, which contains a large number of interactions and forwardings with visitors to the museum, and responds 
promptly and promptly to audiences' questions in private chats, with a significant affinity, Thoughtfulness. [6]

The design styles of foreign digital museums maintain the characteristics of simplicity and focus. The page layout is usually in the form of graphic and text regional layout, such as large pictures across the entire website. It has a strong visual impact. The design style of each page is consistent with the style of the collection displayed on each page. A large amount of white space in the page design makes the website elegant and modern. The most important thing is that the style of the website is the same as the entity of the museum, such as "The British Museum" and "Metropolitan Museum".

\subsection{Brand Image Comparison of Chinese and Foreign Digital Museums}

Brand image can be divided into the brand internal image and external image. The internal image of the brand refers to the image of the brand that people associate with the brand, their cognition of the brand, and the interactive experience of the brand. The external image refers to the cognitive impression left by the brand to consumers, such as the LOGO (LOGOtype), color, and brand evaluation.

Domestic brand image awareness is relatively weak, and the overall design lacks uniformity. The visual effects are not uniform and the color selection is absent, so the brand benefits cannot be communicated to the public in time. However, there are also some brand image designs that are unified and have strong visual effects. For example, the visual image design of Wuqueqi Su-style pub brand-Wuqueqiao-is a thousand-year-old bridge in Suzhou. It has represented love since ancient times and contains ancient people. Yearning for beautiful things, the brand name is fully integrated into the beauty of cultural heritage. Therefore, in the LOGO (LOGOtype) design, the shape of the Suzhou garden doorway is the pattern. The Soviet-style garden buildings and the Jiangnan arch bridge only present half of the shape in the doorway, but this can precisely reflect the Soviet-style charm. A black magpie corresponds to the brand name Wu Que Qi.

Brand image design in foreign countries developed earlier. In terms of logos, fonts, colors, and packaging, brand concepts, and brand emotions were fully integrated into their own products, and the design methods were integrated and unified. For example, the visual image of the "Seine Concert Hall" adopts an abstract depiction similar to that of the concert hall. The unique guidance system and the architectural structure are consistent with creating a unified visual effect. In terms of color, the designer cleverly uses The contrast between black and white forms a sharp contrast, coupled with a simple arrow guide and a sign carrier similar to a music score. The form is novel, and the design is simple and flexible.

\subsection{Comparison of Cultural and Creative Products of Chinese and Foreign Digital Museums}

If products and brands only stay at the functional level, it will be difficult to establish brand loyalty. The dissemination of information has completely broken the geographical and time constraints, and museums also need to undergo digital transformation. [7] The brand without affecting the functionality, try to explore the culture behind the product itself and achieve the spirit of consumers. Culture unites together to give consumers a brand-new experience. Cultural and creative products are an extension of the museum's exhibition function and educational function. They can connect cultural relics with contemporary people's life, aesthetics, and needs, allowing viewers to "bring the museum home" and understand the culture behind the cultural relics during use. As an important place for cultural inheritance and cultural development, museums must fully advance with the times in the era of new media, and make full use of the advantages of new media to improve museum work efficiency and service levels. [8]

The cultural and creative brand of the Palace Museum is second to none in the country, such as the I got it tape. Behind the tape is a copy of the authentic Emperor Kangxi, which best reflects the cultural value. The text content brings a sense of humor that is misplaced. The badge of Thousand Miles of Rivers and Mountains. Moon, with blue-green as the main color, is peaceful and harmonious. The design is taken from Wang Ximeng's A Thousand Miles of Countryside Map. The outer layer 
enters into the bright moon, and the continuous mountains and rivers merge into it, creating a clear water and moon effect.

With the development of science and technology and the continuous improvement of the people's requirements for cultural innovation, the museum's creativity in the way of cultural communication is constantly updated [9]. in the 1980s, under the background of the rise of the "New Museology Movement", European and American museums started a revolution. They no longer only regarded cultural relics as the center, and began to create a people-centered exhibition environment. They pay attention to the feelings of visitors, and start to innovate the development concept of art derivatives. In 1970, a popular British song "Little Yellow Duck" was popular all over the world. The British Museum took advantage of this and gave the little yellow duck business value, and that's how souvenirs of the little yellow duck appeared, such as the little yellow duck wearing Indian feathers, little yellow duck wearing magic armor. Such creative design not only maintains the cuteness of the little yellow duck, but also promotes its own culture to a certain extent. Both digital museums and smart museums use new media technologies to open the cyberspace of physical museums.[10]

\section{Conclusion}

By comparing the development status of digital museums at home and abroad, we can know that digital museums are in line with the development of the times. Since the exposure rate of cultural and creative products has increased in recent years, the number of visits, the discussions of museums, as well as digital museums have increased frequently. They have also been improved greatly. With the rapid development of economy and technology, people are already familiar with the Internet in the era of broadband, space, and high-speed telecommunication networks based on electronic computers and modern communication technologies. The emergence of Internet media and other communication methods has opened up people's understanding of the world and created bridges for people to understand and transform the world. The development of the media has had an impact on the people's art, but at the same time, it has also emphasized the importance of spreading traditional art. In the purpose of inheritance and development, traditional culture must not only adapt to the social environment and constantly adapt to the needs of the times, but also continue to learn and absorb other benefits to pursue promotion.

A museum is a place where the masses radiate their personal creativity. It should create a peaceful and interesting cultural transition for visitors, help visitors think during the tour, rejuvenate and gain emotional, spiritual and cultural comfort. The development of digital museums should establish better interactive relationships with tourists with better social responsibilities, such as educating people, entertaining and creating livelihoods. In the past, many physical museums ignored the interaction between entertainment and leisure. The protection and display of cultural heritage cannot make people understand more accurately and force people to feel discouraged. Therefore, the responsibility of the museum should reflect the organic combination of the three, imitate traditional culture extensively, pay attention to the participation and interaction of tourists, meet the needs of tourists of all ages, and become a place for quality education in museums.

The combination of traditional intangible cultural heritage and digital museums can display shadow puppets in various forms. The use of new media technology and the construction of threedimensional technology help the public visit the digital museum, which is very innovative and convenient. Some works allow people to see the value of traditional folk art features. They have become a symbol of traditional art, making it digitalized, and making it more convenient for people to visit, which allows this traditional Chinese culture and art to spread all over the world. 


\section{References}

[1] Tang Ni. Research on the application of digital museum APP based on mobile media [D]. Southwest Jiaotong University, 2017.

[2] Chen Meizhen, Zhao Wanbing, Ai Ziling. Research on the Visual Design of Domestic Traditional Culture and Art Websites [J]. Beauty and Times (Part 1), 2020(11): 98-102.

[3] Zhi Lee. Research on the application of virtual reality technology in digital museums[D]. Chongqing University, 2017.

[4] Kong Jie. The construction of digital museum from the perspective of digital humanities[J]. Jingu Wenchuang, 2020(25): 56-57.

[5] Du Jingyi. Discussion on the Innovation of the Exhibition Mode of Smart Museum[J]. Popular Literature and Art, 2020(09): 52-53.

[6] Zhao Xue. The development of information dissemination of comprehensive museums in my country under the new media [D]. Yunnan University, 2016.

[7] Ma Boyao, Wang Wei. Museum APP and its user experience status [J]. Drama House, 2020(08):211-212.

[8] Zhang Keji. An analysis of museum development in the era of new media [J]. News Communication, 2021 (02): 111-112.

[9] Qian Dan. Research on the Application of Mixed Reality in Museum Cultural Communication[J]. Beauty and Times (Urban Edition), 2020(09): 89-90.

[10] Li Yichao, Peng Changchang, Qi Guanze. Research on Regional Museums under the Background of New Media [J]. Cultural Relics Appreciation and Appreciation, 2020(22): 108-110. 